\title{
ESPACIALIZAÇÃO DO USO DA TERRA DA MICROBACIA DO CÓRREGO MONTE BELO - BOTUCATU (SP), OBTIDO POR IMAGEM DE SATÉLITE DE 2011 E FOTOGRAFIAS AÉREAS COLORIDAS DE 2000
}

\author{
Yara Manfrin Garcia ${ }^{1}$ \\ Damian Ezequiel Ferreyro ${ }^{2}$ \\ Sérgio Campos ${ }^{3}$
}

RESUMO: O presente trabalho teve como objetivo avaliar as variações de uso e ocupação do solo entre os cenários de 2000 e 2011 da microbacia do córrego Monte Belo - Botucatu (SP). Para tanto, utilizou-se de geotecnologias, sendo a integração de informações realizada no Sistema de Informações Geográficas (SIG) - IDRISI, aliada ao uso de cartas digitais do IBGE, escala 1:50.000, além de fotografias aéreas (2000) e imagens de satélite LANDSAT - 5 (2011). Através dos dados obtidos, foram detectadas três classes de uso do solo sendo que em 2000, elas correspondem ao reflorestamento, pastagem e mata ciliar e em 2011, reflorestamento, mata ciliar e solo exposto. Desta forma, pode-se concluir que as ferramentas de análise baseadas em SIGs trazem a possibilidade de analisar as variações no espaço e no tempo além de resultar em informações que podem subsidiar o planejamento da microbacia do Córrego Monte Belo.

\footnotetext{
${ }^{1}$ Mestranda do Programa de Pós Graduação em Agronomia - Energia na Agricultura - Universidade Estadual Paulista "Júlio de Mesquita Filho"- Faculdade de Ciências Agronômicas (UNESP/FCA). E-mail: yaramanfrin@hotmail.com

${ }^{2}$ Graduando em Engenharia Agronômica, Universidad Nacional de Mar del Plata, Facultad de Ciencias Agrarias. E-mail: damian.ferreyro@gmail.com

${ }^{3}$ Prof. Adjunto, Departamento de Engenharia Rural, Faculdade de Ciências Agronômicas. E-mail: seca@fca.unesp.br
} 
Palavras-Chave: Sistema de Informação Geográfica. Uso e Ocupação do Solo. Preservação Ambiental.

\section{INTRODUÇÃO}

O levantamento das degradações sofridas pelo meio ambiente é de suma importância para o conhecimento da realidade e a busca de sua recuperação. Nesse contexto, o uso adequado da terra, de maneira a protegê-la contra a erosão e visando aumentar gradativamente a sua capacidade produtiva, requer sempre um planejamento inicial, efetivo e eficiente.

Para que se possa estruturar e viabilizar um planejamento agrícola e a implementação de uma política agrícola adequada há necessidade de se ter informações confiáveis e atualizadas referentes ao uso e ocupação da terra.

$\mathrm{Na}$ atividade rural as imagens de satélite permitem fazer vários levantamentos, utilizando basicamente o planejamento e regularização da propriedade. As imagens permitem calcular com maior precisão as áreas de lavouras, matas e pastagens, além de se constituírem um valioso instrumento para a seleção de locais para plantio de culturas anuais, formação de pomares, locação de estradas, represas, etc. Portanto, as imagens de satélite tem condições de oferecer uma visão clara, abrangente e atual do uso da terra.

Desta forma, o presente trabalho tem como objetivos discriminar, mapear e quantificar as áreas de uso da terra da microbacia do Córrego Monte Belo - Botucatu (SP), obtido por imagem de satélite de 2011 e fotografias aéreas coloridas de 2000.

\section{REVISÃO BIBLIOGRÁFICA}

\subsection{Bacia hidrográfica e Planejamento Ambiental}

A bacia hidrográfica é como um conjunto de terras drenadas por um rio e seus afluentes, formada nas regiões mais altas do relevo por divisores de água, onde as águas 
das chuvas, ou escoam superficialmente formando os riachos e rios, ou infiltram no solo para formação de nascentes e do lençol freático. Esses divisores de águas separam uma bacia da outra e, internamente, existem elevações que são denominadas de interflúvios, que dividem sub-bacias hidrográficas (BARRELLA et al., 2001)

As mesmas se tornam um instrumento de planejamento e gestão fundamental e perspectiva ecológica, pois todos os processos e as interações que importam ao planejamento ambiental estarão em alguma estância relacionados a questão dos recursos hídricos (ROSS \& DEL PRETTE, 1998). Vitte \& Guerra (2004) citam que a bacia representa um sistema sobre o qual é possível avalias as ações humanas e seus desdobramentos de forma integrada.

Uma bacia hidrográfica compreende diversos tributários que convergem para um curso principal, carregando uma boa quantidade de material de origem natural e antrópica, se estiver inserido em um núcleo urbano e/ou agrícola, cujas águas têm suas características modificadas. A qualidade de água em qualquer ponto de um rio/tributário reflete a influência da geologia, vegetação, solos, clima e, sobretudo, do homem (MOURA et al., 2010).

As bacias vêm se consolidando como unidade geográfica de planejamento do uso e ocupação das terras, tanto no meio rural quanto urbano, visando o desenvolvimento sustentado no qual se compatibilizam atividades econômicas com preservação ambiental (SOUZA \& FERNANDES, 2000).

\subsection{Geotecnologias}

O uso de tecnologias computacionais na gestão dos recursos naturais e na gestão e monitoramento do território vêm se tornando cada vez mais importantes, recebendo mais atenção por parte de pesquisadores, universidades, empresas e gestores públicos.

Segundo Guerra (1980) apud Flauzino et al. (2010), antes de se pensar em planejar a utilização dos recursos naturais, faz-se necessário o conhecimento prévio dos 
mesmos, ou seja, suas características qualitativas e quantitativas. Uma das tecnologias que possibilitam a caracterização física de uma região é denominada geotecnologia. Esta tecnologia permite o emprego de diversas ferramentas disponíveis para o conhecimento, gestão e monitoramento das bacias hidrográficas de uma região e o aproveitamento dos recursos naturais ali existentes.

As geotecnologias, representadas em especial pelo Sistema de Informação Geográfica (SIG), Sensoriamento Remoto e Sistema de Posicionamento Global (GPS), apresentam uma série de facilidades na geração e produção de dados e informações para o estudo de fenômenos geográficos, como por exemplo, os desastres naturais (COPPOCK, 1995). Tais tecnologias são muito utilizadas na realização de trabalhos na área de geoprocessamento, servindo também para estudar diversas áreas do conhecimento humano.

O Sistema de Informação Geográfica refere-se a aquisição, armazenamento, manipulação, analise e apresentação de dados georreferenciados, ou seja, um sistema de processamento de informação especial (MOURA, 2005).

Segundo Burrough (1992), o SIG é um conjunto de ferramentas para coleta, armazenamento, recuperação, transformação e exibição de dados espaciais do mundo real para um conjunto particular de propósitos.

Os SIG providenciam análises que podem, a partir da noção de localização, prever tendências, hipóteses, cenários futuros, objetivos, problemas ambientais, e verificar o já existente e ocorrido no local de estudo.

Já, o sensoriamento remoto é a ciência e a arte de se obterem informações sobre um objeto, área ou fenômeno, através da análise de dados coletados por aparelhos denominados sensores, que não entram em contato direto com os alvos em estudo (NOVO, 2008).

Utilizando estas ferramentas pode-se produzir informações em pouco tempo e com baixo custo, combinando informações de dados espaciais multi-fontes a fim de analisar as interações existentes entre as variáveis, elaborar modelos preventivos e dar suporte as tomadas de decisões (BONHAM-CARTER, 1996). 


\section{S Fen Fórum Ambiental \\ da Alta Paulista

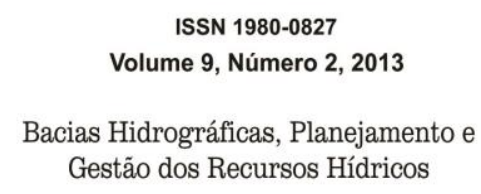

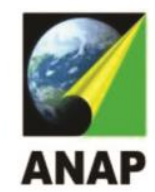

Para este trabalho, foi utilizado o SIG Idrisi que segundo Eastman (1997), é um software para processamento de imagens; líder na funcionalidade analítica raster, cobrindo todo o espectro de necessidade de Sistema de Informação Geográfica e de sensoriamento remoto, desde a consulta ao banco de dados e modelagem espacial até realce e classificação de imagens, possibilitando, também, pela divergência de cores, calcular diferenças de áreas em uma mesma superfície.

Este sistema foi desenvolvido e lançado em 1987, pela Clark University, Massashussets, é baseado na forma raster de representação de dados. E segundo Teixeira et al. (1992), apresenta uma característica importante, possibilitando que o usuário escreva programas específicos para ampliar a sua gama de aplicações.

\subsection{Uso e Ocupação do Solo}

Segundo Dainese (2001) apud Mileski (2011) a maneira como o homem interfere no meio ambiente para produzir alimentos sempre foi agressiva. No entanto, o homem depende cada vez mais do convívio harmonioso com a natureza. Devido a isso, a necessidade de planejamento racional do uso do meio ambiente é extremamente importante.

O uso e a ocupação do solo são determinados pelo conjunto de atividades de uma sociedade sobre o espaço. Seu conhecimento, bem como sua situação, fornece informações essenciais para um planejamento.

Através do uso e a ocupação adequados acompanhados de um zoneamento, pode-se minimizar conflitos entre usos e atividades incompatíveis ou inconvenientes, assim como um aproveitamento socialmente justo e racional do solo. Também, promove a utilização adequada dos recursos naturais disponíveis, bem como proteção, preservação e recuperação do ambiente natural e a utilização do bem em conformidade com as funções sociais da sociedade. Esse instrumento é fundamental para o ordenamento territorial (PACHECO, 2011). 
Segundo Campos (2001), o uso adequado do solo exige a utilização de várias técnicas de manejo e conservação do mesmo, sendo também variados os níveis de complexidade apresentados por cada uma. Para o autor, a maioria das áreas de cultivo hoje no Estado de São Paulo sofreram uma conseqüência de ações que reduziram drasticamente sua capacidade produtiva, e como agente principal do depauperamento das terras pode-se citar a erosão hídrica, sendo que a erosão do solo influencia a produtividade alterando os fatores que a limitam.

O uso adequado da terra é o primeiro passo em direção a uma agricultura correta. Para isso, cada parcela de terra deve ser utilizada de acordo com a sua capacidade de sustentação e produtividade econômica, de forma que os recursos naturais sejam colocados à disposição do homem para melhor uso e benefício, procurando ao mesmo tempo preservar estes recursos para gerações futuras (LEPSCH et al., 1991).

\section{MATERIAL E MÉTODOS}

A microbacia do Córrego Monte Belo está situada na porção norte do município de Botucatu com uma área de 1697,22ha, situando-se geograficamente entre as coordenadas: latitude $22^{\circ} 45^{\prime}$ a $22^{\circ} 48^{\prime} \mathrm{S}$ e longitudes $48^{\circ} 15^{\prime}$ a $48^{\circ} 21^{\prime}$ W Gr. (Figura 1).

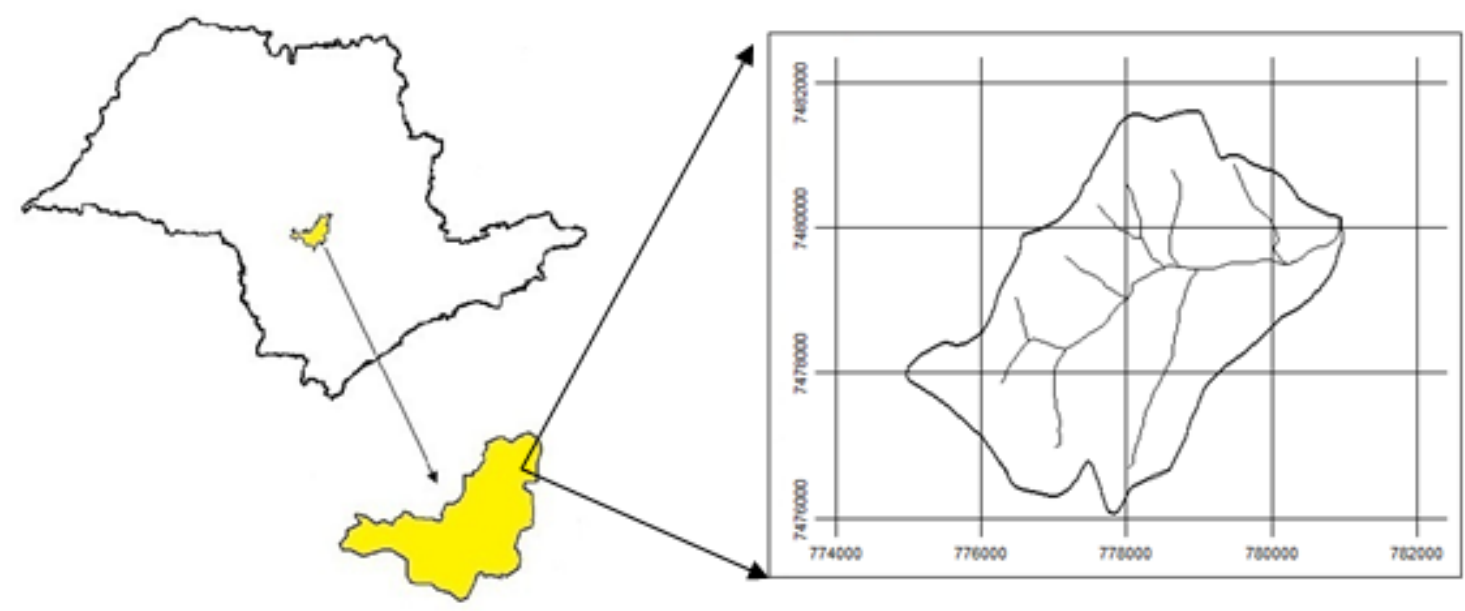

Figura 1 - Localização da microbacia do Córrego Monte Belo no estado de São Paulo. 
Segundo OLIVEIRA et al. (1999), os solos ocorrentes na área foram classificados como: LVA36 - Distróficos rel. ondulado + Latossolos Vermelhos Distróficos rel. Plano e suave ondulado ambos A moderado text. média e NV3 - Eutróficos A moderado e chernozêmico rel. ondulado e forte ondulado + Neossolos Litólicos Eutróficos A moderado rel. forte ondulado ambos text. argilosa.

O clima predominante do município, segundo a classificação de Köppen, é o Cwa Clima Mesotérmico de Inverno Seco - em que a temperatura do mês mais frio é inferior a $18^{\circ} \mathrm{C}$ e do mês mais quente ultrapassa os $22^{\circ} \mathrm{C}$.

Os pontos de controle (coordenadas) para o georreferenciamento e os pontos de máxima altitude para digitalização do limite da microbacia tiveram como base a carta planialtimétrica em formato digital, editada pelo Instituto Brasileiro de Geografia e Estatística - IBGE (1969), folha de Botucatu (SF-22-R-IV-3), em escala 1:50000.

As áreas de cobertura e uso do solo em 1962 foram obtidas através de fotografias aéreas e as de 2011, através de imagens de satélite digital, na qual utilizou as bandas 3 , 4 e 5 do sensor "Thematic Mapper" do LANDSAT - 5, da órbita 220, ponto 76, quadrante A.

No desenvolvimento do trabalho foi utilizado um estereoscópio de espelhos modelo ST4 da marca WILD para a observação estereoscópica de fotografias aéreas e um transformador aerofotográfico (Aerosketchmaster). A transferência, dos elementos de interesse, das fotos para o mapa base (obtido através da carta do IBGE) foi efetuada com o auxílio do transformador aerofotográfico, utilizando o modo redução, obtendo-se assim um mapa com escala corrigida.

O Sistema de Informações Geográficas - IDRISI Selva foi usado no processamento das informações, georreferenciamento, composição colorida das imagem de satélite das bandas 3, 4 e 5 em RGB (Red Green Blue) - apresenta uma boa discriminação visual dos alvos, possibilitando a identificação dos padrões de uso da terra de maneira lógica. Esta composição apresenta os corpos d'água em tons azulados, as florestas e outras formas de vegetações em tons esverdeados e os solos expostos em 
tons avermelhados -, conversão dos dados vetoriais em imagem raster, elaboração dos mapas de uso e ocupação do solo, e no cálculo das áreas e porcentagens de cada uso

O software CartaLinx foi utilizado na digitalização do limite da microbacia, da rede de drenagem e das áreas de cobertura vegetal, obtidas através de imagens de satélite e fotografias aéreas.

\section{RESULTADOS E DISCUSSÃO}

O levantamento do uso do solo, em uma determinada região, torna-se um aspecto de interesse fundamental para a compreensão dos padrões de organização do espaço já que o conhecimento das alterações ambientais, provocadas pela ação antrópica, possibilita uma visão dos problemas existentes e produz subsídios para gestão dos recursos naturais. É condição primordial para se programar uma política de uso racional do solo e de respeito à suscetibilidade e capacidade de suporte do meio ambiente aos impactos antrópicos, possibilitando o desenvolvimento sócio-econômico sustentável (NARDINI, 2009).

Para o mapeamento do uso e ocupação do solo de 2000, foram encontrados três classes de uso e ocupação do solo, sendo: reflorestamento, pastagem e mata ciliar, conforme apresentado na Figura 2. 


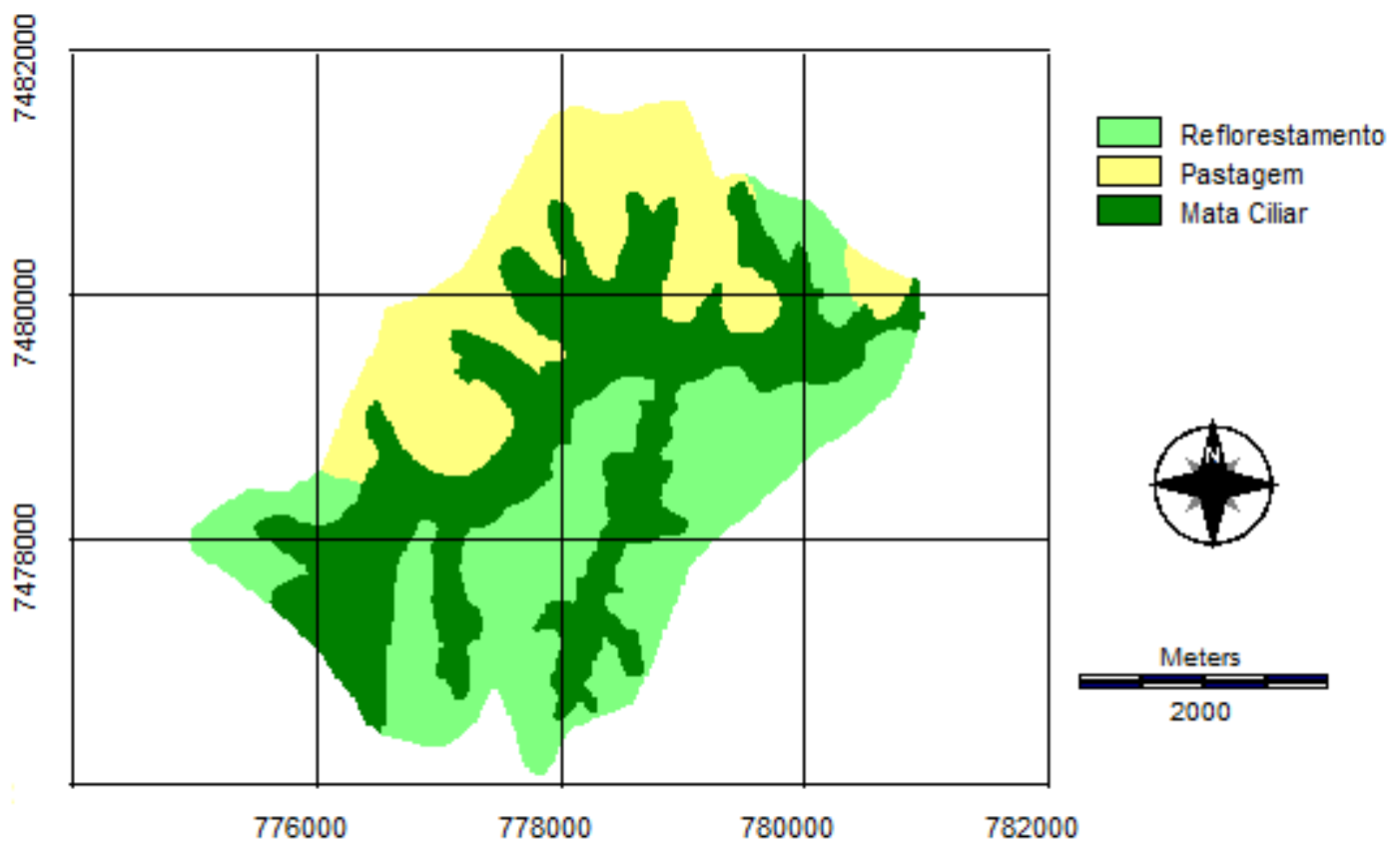

Figura 2 - Mapa de uso e ocupação do solo obtido por fotografias aéreas de 2000.

No mapeamento do uso e ocupação do solo em 2011, também constatou-se três classes de uso divididas em reflorestamento, mata ciliar e solo exposto, Figura 3.

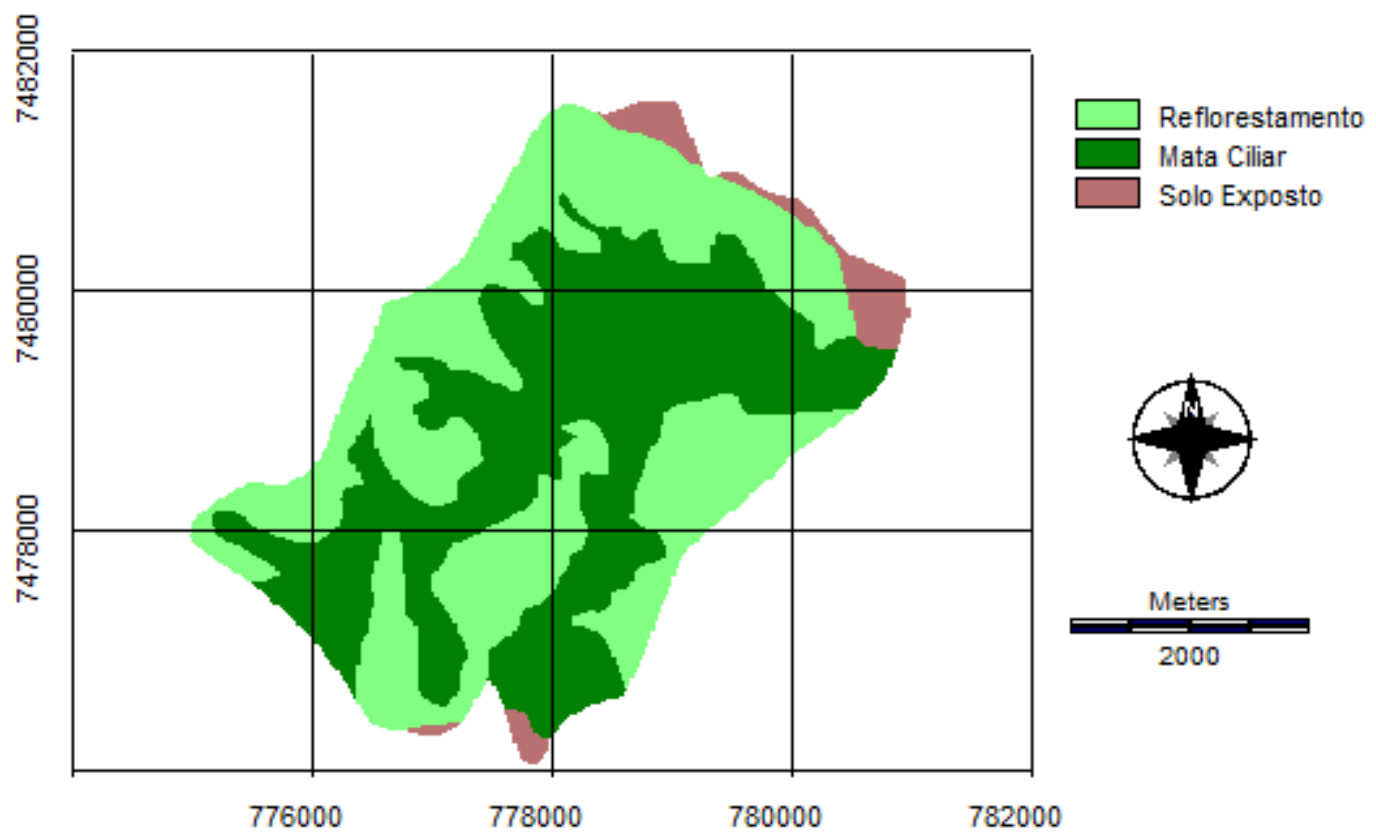

Figura 3 - Mapa de uso e ocupação do solo obtido por imagens de satélite de 2011. 


\section{Then Fórum Ambiental \\ da Alta Paulista \\ ISSN 1980-0827 \\ Volume 9, Número 2, 2013 \\ Bacias Hidrográficas, Planejamento e

Os resultados do uso da terra na microbacia do Ribeirão São Pedro - Botucatu (SP) mostraram que o reflorestamento e a mata ciliar ocuparam a maior parte da área tanto em 2000 quanto em 2011.

A mata ciliar em 2000 ocupou 664,11ha $(39,13 \%)$ do total da área e em 2011, 804,12 ha representando $47,38 \%$. Se fossemos entrar em discussão sobre a questão das Áreas de Preservação Permanente, poderiamos dizer que visualmente, aparecem preservadas estando de acordo com a legislação ambiental vigente, no caso o Código Florestal porém, para um diagnóstico preciso, seria necessário a geração de buffers dessas áreas com a metragem adequada (no caso, considerando os cursos d'água de até 10 metros de largura, as APP seriam de 30 metros de cada lado nos cursos d'água e 50 nas metros nas nascentes).

O reflorestamento, representou 612,18ha (36,07\%) do total da área em 2000 e $818,62 \mathrm{ha}(48,23 \%)$ em 2011. Já, as pastagens que em 2000 correspondia a 420,93ha, não foi encontrada na análise de 2011, o mesmo acontecendo com a classe de solo exposto, sendo que foi evidenciado apenas nas imagens de satélite, representando assim 74,48 ha o que corresponde a apenas $4,39 \%$ do total da área.

A seguir, na Tabela 1, são apresentados os resultados de uso e ocupação do solo encontrados nas análises de uso e ocupação do solo por meio de fotografias aéreas (2000) e imagens de satélite (2011).

Tabela 1 - Distribuição das áreas e porcentagens de uso e ocupação do solo em 2000 e 2011.

\begin{tabular}{ccccc}
\hline $\begin{array}{c}\text { Classes de Uso } \\
\text { do solo }\end{array}$ & \multicolumn{5}{c}{ Uso e Ocupação do Solo } \\
\hline & \multicolumn{2}{c}{2000} & \multicolumn{2}{c}{$\mathbf{2 0 1 1}$} \\
ha & $\%$ & ha & $\%$ \\
Reflorestamento & 612,18 & 36,07 & 818,62 & 48,23 \\
Pastagem & 420,93 & 24,80 & - & - \\
Mata Ciliar & 664,11 & 39,13 & 804,12 & 47,38 \\
Solo Exposto & - & - & 74,48 & 4,39 \\
\hline Total & 1697,22 & 100 & 1697,22 & 100 \\
\hline
\end{tabular}




\section{Then

Vale enfatizar que o uso racional do solo deve ser baseado em atividades produtivas que considerem o potencial de terras para diferentes formas de uso, fundamentado no conhecimento das potencialidades e fragilidade dos ambientes, de forma a garantir a produção e reduzir os processos geradores de desequilíbrio ambiental, com base em tecnologias técnica e ambientalmente apropriadas (GEBLER \& PALHARES, 2007).

\section{CONCLUSÕES}

A identificação do uso e ocupação do solo constitui-se em um importante elemento para o estudo ligado à temática ambiental. Tal estudo proporciona visualizar parâmetros quantitativos e qualitativos que se conhecidos e compreendidos, poderão trazer inúmeros benefícios ao ambiente e consequentemente influenciando na qualidade de vida da população.

As geotecnologias se apresentaram como um instrumento de extrema importância para as análises sendo que, as imagens de satélite e fotografias aéreas permitiram o mapeamento do uso e ocupação do solo da microbacia de maneira rápida, além de fornecer um excelente banco de dados para futuros planejamentos da área.

O Sistema de Informação Geográfica foi eficiente na identificação, mapeamento e na determinação dos usos assim, o SIG - IDRISI, através de seus diferentes módulos para georreferenciamento, classificação digital do uso e ocupação do solo e modelo matemático permitiu a discriminação dos seguintes usos: reflorestamento, pastagem, mata ciliar e solo exposto.

\section{REFERÊNCIAS}

BARRELLA, W. et al. As Relações Entre as Matas Ciliares, os Rios e os Peixes. In: RODRIGUES \& LEITÃO FILHO (org.). Matas Ciliares: Conservação e Recuperação. São Paulo, Ed. Universidade de São Paulo, FAPESP, 2001. 
BOHNHAM-CARTER, G. F. Geographic Information Systems for Geoscientists: Modeling with GIS. Ottawa: Pergamon, 1996. 398 p.

BURROUGH, P. A. Principles of Geographical Information System for Land Resources Assessment. Oxford University Press: New York, 1992. 194p.

CAMPOS, S. P. Planejamento agroambiental de uma microbacia hidrográfica utilizando um Sistema de Informações Geográficas. Botucatu, 2001, 137 p. Tese (Doutorado em Agronomia/ Energia na Agricultura), Faculdade de Ciências Agronômicas, Universidade Estadual Paulista.

COPPOCK, J. T. GIS and natural hazards: an overview form a GIS perspective. In: CARRARA, A.; GUZZETTI, E. Geographical Information systems in assessing natural hazards. Dordrecht: Kluwer Academic Publishers. Cap 2, p. 21-34. 1995.

EASTMAN, J. R. IDRISI for windows: user's guide, version 2.0. Clark University, 1997. $350 p$.

FLAUZINO, F. S.; SILVA, M. K. A.; NISHIYAMA, L.; ROSA, R. Geotecnologias aplicadas à gestão dos recursos naturais da bacia hidrográfica do Rio Paranaíba no cerrado mineiro. Soc. nat. (Online) [online]. 2010, vol.22, n.1, pp. 75-91. ISSN 1982-4513.

GEBLER, L.; PALHARES, J.C.P. (Eds.) Gestão ambiental na agropecuária. Brasília: Embrapa Informação Tecnológica. 2007. 310p.

IBGE. INSTITUTO BRASILEIRO DE GEOGRAFIA E ESTATÍSTICA. Carta topográfica. Serviço gráfico do IBGE, 1969. Escala 1:50.000.

INPE. INSTITUTO NACIONAL DE PESQUISAS ESPACIAIS. Divisão de Geração de Imagens (DGI-INPE). Catálogo de imagens. Disponível em:

<http://www.dgi.inpe.br/>. Acesso em: 15 out. 2012.

LEPSCH, J. F. et al. Manual para levantamento utilitário do meio físico e classificação de terras no sistema de capacidade de uso. Campinas, Soc. Bras. Cien. do Solo, 1991. 175 p.

MILESKI, M. M. Geoprocessamento Aplicado no Uso e Ocupação do Solo no Município de Lençóis Paulista - SP. Dissertação (Mestrado em Agronomia/ Energia na Agricultura)-Faculdade de Ciências Agronômicas, Universidade Estadual Paulista, Botucatu, 2011. 


\section{Then Fórum Ambiental \\ da Alta Paulista \\ ISSN 1980-0827 \\ Volume 9, Número 2, 2013 \\ Bacias Hidrográficas, Planejamento e

MOURA, L. H. A.; BOAVENTURA, G. R.; PINELLI, M. P. A qualidade de água como indicador de uso e ocupação do solo: bacia do Gama - Distrito Federal. Quím. Nova [online]. 2010, vol.33, n.1, pp. 97-103. ISSN 0100-4042.

MOURA, A. C. M. Geoprocessamento na gestão e Planejamento urbano. Belo Horizonte, 2005.

NARDINI, R. C. Determinação do conflito de uso e ocupação do solo em áreas de preservação permanente da microbacia do ribeirão Água-Fria, Bofete (SP), visando a conservação dos recursos hídricos. 2009. 61f. Dissertação (Mestrado em Agronomia//rrigação e Drenagem)-Faculdade de Ciências Agronômicas, Universidade Estadual Paulista. Botucatu-SP. UNESP. 2009.

NOVO, E. M. L. M. Sensoriamento Remoto: Princípios e aplicações. São Paulo. Ed. Edgard Blucher, 2008. 363p.

OLIVEIRA, J. B. de; et al. Solos do Estado de São Paulo: descrição das classes registradas no mapa pedológico. Boletim Científico n 45 IAC. Campinas, 1999. 108p.

PACHECO, A. Uso e Ocupação do Solo. 2011. Disponível em:

$<$ http://www.redeambiente.org.br/forea/doc-

forea\%202011/O\%20USO\%20E\%20A\%20OCUPA\%C3\%87\%C3\%83O\%20DO\%20SOLO .pdf>. Acesso em: 04 maio 2013.

ROSS, J. L. S.; DEL PRETTE, M. E. Recursos Hídricos e as Bacias Hidrográficas: Âncoras do Planejamento e Gestão Ambiental. Revista do Departamento de Geografia/FFLCH/USP. № 12, 1998.

SOUZA, E. R. de; FERNANDES, M. R. Sub-bacias hidrográficas: unidades básicas para o planejamento e a gestão sustentáveis das atividades rurais. Informe Agropecuário, Belo Horizonte, v.21, n.207, p.15-20, nov./dez. 2000.

TEIXEIRA, A. L. A.; MORETTI, E.; CHRISTOFOLETTI, A. Introdução aos Sistemas de Informação Geográfica. Rio Claro SP., 1992, 80p.

VITTE, A. C.; GUERRA. A. J. T. (org). Reflexões sobre a geografia Física no Brasil. Rio de Janeiro: Bertrand Brasil, 2004. 